\title{
Activity in Prelimbic Cortex Is Necessary for the Expression of Learned, But Not Innate, Fears
}

\author{
Kevin A. Corcoran and Gregory J. Quirk \\ Department of Physiology, Ponce School of Medicine, Ponce, Puerto Rico 00732
}

The amygdala has long been considered to be both necessary and sufficient for classical fear conditioning, but recent evidence suggests that the medial prefrontal cortex (mPFC) may also be involved. The prelimbic (PL) subregion of mPFC projects to the amygdala, and neurons in PL show fear-related increases in activity. It is unknown, however, whether PL activity is necessary for expression of learned fears, expression of innate fears, or the learning of fear associations. To address this, we used the sodium channel blocker tetrodotoxin to inactivate PL during fear learning or expression. Inactivation of PL reduced freezing to both a tone and a context that had been previously paired with footshock (learned fear) but had no effect on freezing to a cat (innate fear). Inactivation of PL before conditioning, however, did not prevent the formation of auditory or contextual fear memories. Thus, activity in PL is critical for the expression, but not the acquisition, of learned fears. We suggest that PL integrates information from auditory and contextual inputs and regulates expression of fear memories via projections to the basal nucleus of the amygdala.

Key words: tetrodotoxin; prefrontal cortex; inactivation; rat; cat; predator

\section{Introduction}

An organism's survival depends on its ability to respond appropriately to threatening stimuli. Fear responses to such stimuli can be either learned or innate. A set of neural circuits mediating fear learning and expression has been conserved across mammalian species. At the heart of this fear circuit lies the amygdala, which receives convergent information about conditioned (learned) (CS) and unconditioned (innate) stimuli and stores associative memories of these stimuli (LeDoux, 2000). In support of this, lesions of the amygdala eliminate the ability of rats to learn fear associations (Iwata et al., 1986; Goosens and Maren, 2001), and lesions made after conditioning abolish previously learned fear responses (Kim and Davis, 1993; Anglada-Figueroa and Quirk, 2005) as well as fear responses to a predator (Blanchard and Blanchard, 1972). Thus, the amygdala is necessary for both the acquisition and expression of fear responses.

In contrast to the amygdala, the cortex is thought to be unnecessary for fear learning, because pretraining lesions of various cortical regions do not disrupt acquisition of conditioned fear (Romanski and LeDoux, 1992; Morgan et al., 1993; Campeau and Davis, 1995; Quirk et al., 2000). This idea has been challenged recently, however, by observations that some types of fear learning require activation of kinases and dopamine receptors in the

Received 0ct. 25, 2006; revised Dec. 14, 2006; accepted Dec. 15, 2006.

This work was supported by National Institutes of Health Grants MH058883, MH072156, and GM008239 (G.J.Q.) and MH077444 (K.A.C.). We thank Mohammed Milad and Jeffrey Rosen for their helpful comments on this manuscript.

Correspondence should be addressed to Kevin A. Corcoran, Department of Physiology, Ponce School of Medicine, P.0. Box 7004, Ponce, Puerto Rico 00732-7004. E-mail: kevincorcoran@gmail.com.

G. J. Quirk's and K. A. Corcoran's present address: Department of Psychiatry, University of Puerto Rico School of Medicine, P.0. Box 365067, San Juan, Puerto Rico 00936.

DOI:10.1523/JNEUROSCI.5327-06.2007

Copyright $\odot 2007$ Society for Neuroscience $\quad$ 0270-6474/07/270840-05\$15.00/0 medial prefrontal cortex (mPFC) (Runyan et al., 2004; Laviolette et al., 2005) and that pharmacological inactivation of mPFC reduces expression of conditioned fear (Sierra-Mercado et al., 2006). Thus, despite negative lesion findings, activity in the mPFC may be important for fear acquisition or expression in an intact animal.

The prelimbic $(\mathrm{PL})$ subregion of $\mathrm{mPFC}$ sends robust projections to the basal nucleus of the amygdala (McDonald et al., 1996; Vertes, 2004), and neurons in PL show conditioning-induced plasticity (Baeg et al., 2001; Gilmartin and McEchron, 2005; Laviolette et al., 2005). Lesions of PL do not prevent acquisition or expression of conditioned fear (Rosen et al., 1992; Morgan et al., 1993; Quirk et al., 2000), but it is not known whether PL activity in the intact animal is essential for either process. To address this, we inactivated PL with the sodium channel blocker tetrodotoxin (TTX) under three conditions: before auditory or contextual conditioning, after auditory or contextual conditioning, or before exposure to a predator. This design allowed us to determine the extent to which the involvement of PL in fear learning might depend on factors such as the nature of a fear stimulus (learned vs innate), stimulus modality, and phase of learning.

\section{Materials and Methods}

Subjects. Male Sprague Dawley rats (270-320 g) were obtained, housed, and handled as described previously (Quirk et al., 2000). Food was restricted to $18 \mathrm{~g} / \mathrm{d}$ until rats reached $85 \%$ of their free-feeding weight. They were then trained to press a bar for food on a variable interval schedule of reinforcement (VI-60). Throughout all conditioned fear experiments, rats were able to press for food to maintain a constant level of activity against which freezing could be reliably measured (Quirk et al., 2000). All procedures were approved by the Institutional Animal Care and Use Committee of the Ponce School of Medicine in compliance with National Institutes of Health guidelines. 
Surgery. Rats were anesthetized with ketamine (80-90 mg/kg, i.p.)/ xylazine $(5-10 \mathrm{mg} / \mathrm{kg}$, i.p.) and implanted with a single stainless steel guide cannula (26 gauge; Plastics One, Roanoke, VA) aimed at the midline. Coordinates were $2.8 \mathrm{~mm}$ anterior, $0.9 \mathrm{~mm}$ lateral, $2.9 \mathrm{~mm}$ ventral to bregma, and the cannulas were angled $13^{\circ}$ toward the midline in the coronal plane. Rats were allowed $7 \mathrm{~d}$ to recover from surgery before behavioral testing.

TTX infusions. Inactivation of PL was achieved via infusion of TTX (5 ng/0.3 $\mu$ l; Sigma, St. Louis, MO) dissolved in artificial CSF (ACSF). We chose to use TTX to block activity in PL neurons as well as in afferent axons terminating in PL. Infusion cannulas (33 gauge; Plastics One) extended $1 \mathrm{~mm}$ past the end of the guide cannulas. Drugs were infused at a rate of $0.15 \mu \mathrm{l} / \mathrm{min}$ for $2 \mathrm{~min}$, for a total volume of $0.3 \mu \mathrm{l}$. Infusion cannulas were left in place for $1 \mathrm{~min}$ to allow for diffusion of the drug. In all experiments, infusions were performed $45 \mathrm{~min}$ before behavioral testing.

Pretesting inactivation of PL. All conditioning experiments were performed in four identical operant conditioning chambers, as described previously (Quirk et al., 2000). Food was available on a VI-60 schedule during all sessions. Between rats, shock grids were cleaned with soap and water, and the chamber walls were wiped clean.

Rats were conditioned to either a tone or a context paired with footshock. On day 1 of auditory conditioning, rats were given seven tones (30 $\mathrm{s} ; 75 \mathrm{~dB} ; 4 \mathrm{kHz})$ that coterminated with footshocks $(0.5 \mathrm{~s} ; 0.50 \mathrm{~mA})$. The interval between tone presentations was variable with an average of 3 min. On day 2, rats were returned to the chambers for testing, which consisted of two tones in the absence of footshock. Forty-five minutes before testing, rats received intra-PL infusions of ACSF $(n=10)$ or TTX $(n=10)$.

For context conditioning, rats were given four unsignaled footshocks ( $1 \mathrm{~s} ; 0.8 \mathrm{~mA}$ ) on day 1 . The shocks were spaced $3 \mathrm{~min}$ apart, beginning 5 min after the rats were placed in the conditioning chambers. Rats were returned to their home cages $3 \mathrm{~min}$ after the last footshock. On day 2, rats were returned to the chambers for a $5 \mathrm{~min}$ test. Rats received intra-PL infusions of ACSF $(n=8)$ or TTX $(n=8) 45 \mathrm{~min}$ before testing.

Test for predator fear. A subset of the rats used in the previous experiments was tested for innate fear to a live cat (Blanchard and Blanchard, 1972). The apparatus used was adapted from that used by Pentkowski et al. (2006). A rectangular arena $(91.5 \mathrm{~cm}$ long $\times 51 \mathrm{~cm}$ deep $\times 61 \mathrm{~cm}$ tall $)$ was divided into two rat chambers and a cat compartment. One end of each rat chamber faced the cat compartment through a wire mesh screen. Rats were given a $3 \mathrm{~min}$ preexposure session to habituate them to the novel environment. They were then returned to their home cages and infused with either ACSF $(n=9)$ or TTX $(n=9)$. Forty-five minutes later, they were returned to the chambers and, after $5 \mathrm{~min}$, a female domestic cat was introduced into the cat compartment. Rats were exposed to the cat for $5 \mathrm{~min}$ and returned to their home cages.

Preconditioning inactivation of PL. Rats were conditioned and tested for fear to auditory and contextual stimuli as described above. In these experiments, however, PL infusions occurred $45 \mathrm{~min}$ before fear acquisition on day 1 , and rats were tested drug-free on day 2 . For auditory conditioning (ACSF, $n=9$; TTX, $n=8$ ), the conditioning and testing phases were as described above. For context conditioning, we reconditioned rats that had been used in the auditory pretesting inactivation experiment. In this experiment (ACSF, $n=10$; TTX, $n=10$ ), rats received only two unsignaled footshocks during conditioning and were given a 5 min context test the following day, drug free.

Open field. Rats were tested for locomotion and anxiety in an open field $(91.5 \times 91.5 \times 61 \mathrm{~cm})$. Grid lines drawn on the floor of the arena divided it into peripheral (within $15.25 \mathrm{~cm}$ of the walls) and central $(61 \times$ $61 \mathrm{~cm}$ ) regions of approximately equal area. Rats were given infusions of ACSF $(n=10)$ or TTX $(n=10) 45$ min before a 10 min session in the arena.

Data collection and analysis. For all experiments, behavior was videotaped for off-line analysis. Freezing during the contextual and auditory conditioning experiments was quantified from digitized videos using Freezescan software (Clever Systems, Reston, VA) and expressed as the percentage of the CS the rats were motionless. In the auditory conditioning experiments, we also assessed suppression of bar pressing as an addi-

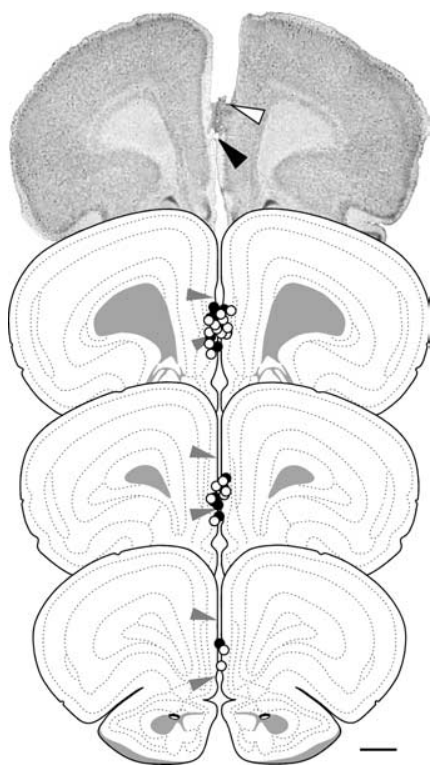

Figure 1. Cannula placements in PL. The photomicrograph shows a thionin-stained coronal section with a representative cannula placement in PL. The white arrow indicates the end of the guide cannula, and the black arrow indicates the tip of the infusion cannula. Illustrated below is the location of guide cannulas for TTX (filled circles) and ACSF (open circles) rats across all experiments. Infusion cannula tips extended $1 \mathrm{~mm}$ beyond the guide cannulas. Gray arrows indicate the dorsal and ventral limits of PL. Scale bar, $1 \mathrm{~mm}$. Atlas templates adapted from Swanson (1992).

tional measure of conditioned fear [suppression $=($ pretone rate - tone rate)/(pretone rate + tone rate)]. A suppression ratio of 0 indicates no suppression of bar pressing, and a ratio of 1.0 indicates maximal suppression. For the innate fear and open-field experiments, behavior was scored by observers blind to the rats' infusions. For all experiments, group differences were determined using ANOVA or Student's $t$ tests. After significant main effects, post hoc comparisons were performed using Scheffé tests. After behavioral procedures were completed, histological verification of cannula placements was performed on thionin-stained coronal sections taken through mPFC.

\section{Results \\ Histology}

Guide cannulas were aimed at the PL subdivision of mPFC. Figure 1 shows a photomicrograph of a representative guide cannula placement in PL, together with an illustration of cannula placements for all rats. A total of 53 rats were used across all experiments.

\section{Inactivation of PL disrupts the expression of learned fear}

To test the role of PL in conditioned fear expression, rats were fear conditioned using auditory or context CSs. The following day, rats were infused with TTX or ACSF into PL before testing for fear (Fig. 2). For both auditory and context conditioning, all rats acquired similarly high levels of fear during the conditioning sessions. The day after conditioning, inactivation of PL decreased conditioned freezing to both tone and context by $\sim 80 \%$ [tone: ACSF, 69\%; TTX, 14\%; $t_{(18)}=4.30 ; p<0.001$ (Fig. 2A); context: ACSF, 65\%; TTX, 9\%; $t_{(14)}=4.37 ; p<0.001$ (Fig. $2 B$ )]. Inactivation similarly reduced conditioned suppression of bar pressing during the tone, as evidenced by a significant reduction in the suppression ratio (ACSF, 0.95; TTX, $0.44 ; t_{(18)}=3.57 ; p=0.002$ ). Thus, activity in PL is necessary for the expression of learned fears. 

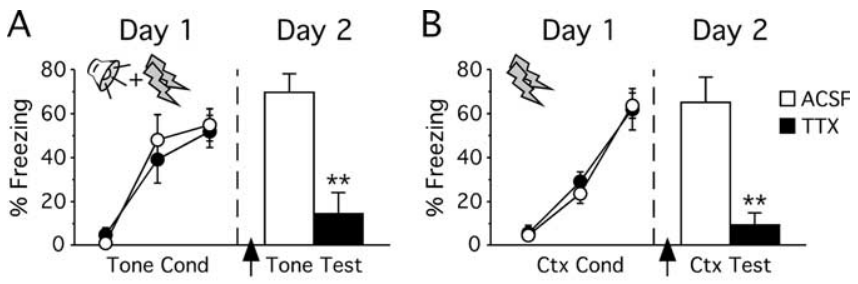

C

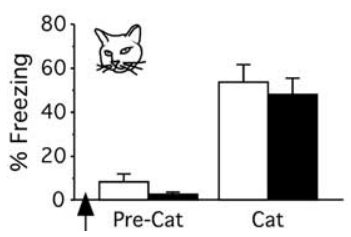

$\mathrm{D}$

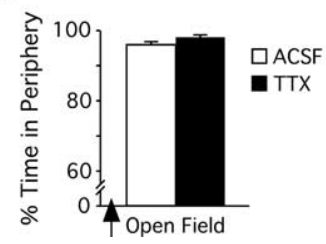

Figure 2. $\mathrm{PL}$ inactivation decreases the expression of learned, but not innate, fear. $\boldsymbol{A}, \boldsymbol{B}$, Infusion of TTX into PL reduced freezing to previously conditioned auditory $(\boldsymbol{A})$ or contextual $(C \mathrm{tx})(\boldsymbol{B})$ conditioned stimuli $\left({ }^{* *} p<0.001\right)$. Data are shown in blocks of two trials. $\boldsymbol{C}, \boldsymbol{D}, \mathrm{PL}$ inactivation did not reduce fear to two innate fear stimuli: a live cat $(\boldsymbol{C})$ or an open field $(\boldsymbol{D})$.

\section{Inactivation of PL does not disrupt the expression of innate fear}

We next tested whether activity in PL is also necessary for the expression of innate fear. Rats were infused with TTX or ACSF and placed in a small arena $45 \mathrm{~min}$ after infusion. After $5 \mathrm{~min}$, a cat was placed in an arena adjacent to the rat, separated by a wire screen. Before cat exposure, rats showed negligible freezing. In the presence of the cat, ACSF-infused rats showed levels of freezing comparable with that elicited by the conditioned tone and context. In contrast to the conditioning experiments, however, infusion of TTX into PL did not reduce freezing to the cat (ACSF, $53 \%$; TTX, $\left.48 \% ; t_{(16)}=0.51 ; p=0.62\right)($ Fig. $2 C$ ).

Another innate fear in rats is the fear of open spaces. Rats were infused with TTX or ACSF before a 10 min session in an open field, in which normal rats prefer to spend time in the periphery (close to the walls). The percentage of time spent in the periphery of the open field did not significantly differ between groups (ACSF, 96\%; TTX, 98\%; $t_{(18)}=1.92 ; p=0.07$ ) (Fig. 2D). Thus, $\mathrm{PL}$ activity is not required for expression of fear to either predators or open spaces.

\section{Inactivation of PL before conditioning does not prevent fear learning}

We next determined whether activity in PL is necessary for fear acquisition by infusing TTX before conditioning. Replicating our findings in the previous experiments, inactivation of PL significantly reduced freezing during the conditioning session (Fig. 3). In the last block of auditory conditioning (Fig. $3 A$ ), vehicle and TTX-infused rats froze 73 and 27\%, respectively. ANOVA revealed significant main effects of infusion $\left(F_{(1,15)}=12.2 ; p=\right.$ $0.003)$ and trial block $\left(F_{(2,30)}=28.0 ; p<0.001\right)$ and a significant infusion by trial block interaction $\left(F_{(2,30)}=7.9 ; p=0.002\right)$. During context conditioning, TTX similarly reduced the expression of freezing (Fig. $3 B$ ). In the last post-shock period, ACSF- and TTX-infused rats froze 67 and 28\%, respectively. ANOVA revealed significant main effects of infusion $\left(F_{(1,18)}=12.1 ; p=\right.$ $0.003)$ and trial $\left(F_{(2,36)}=46.5 ; p<0.001\right)$ and a significant infusion by trial interaction $\left(F_{(2,36)}=10.3 ; p<0.001\right)$.

Despite reduced freezing during training, TTX-infused rats showed normal fear memory the following day, when tested drug free. In the tone conditioning experiment, TTX- and ACSFinfused rats showed equivalently high levels of tone-induced
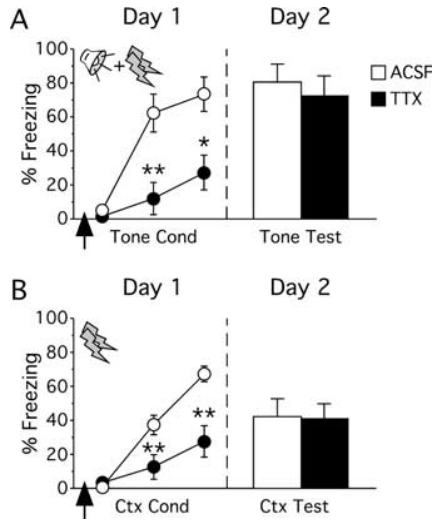

Figure 3. PL inactivation does not prevent the acquisition of conditioned fear. $A, B$, Pretraining inactivation of PL decreased freezing during acquisition of fear to auditory $(\boldsymbol{A})$ or contextual $(\mathrm{Ctx})(\boldsymbol{B})$ conditioned stimuli $\left({ }^{*} p<0.01 ;{ }^{* *} p \leq 0.001\right)$. The following day, however, TTXinfused rats showed normal levels of fear. Data in $A$ are presented as blocks of two trials; data in $\boldsymbol{B}$ are presented as single trials. Thus, PL is not an essential site of plasticity for the acquisition of conditioned fear.

freezing (ACSF, 81\%; TTX, 72\%; $\left.t_{(15)}=0.52 ; p=0.61\right)($ Fig. $3 A)$ and tone-induced suppression of bar pressing (ACSF, 0.93; TTX, $\left.0.87 ; t_{(15)}=0.48 ; p=0.64\right)$. In the context conditioning experiment, all rats showed equivalent levels of context-induced freezing (ACSF, 42\%; TTX, 41\%; $t_{(18)}=0.09 ; p=0.93$ ) (Fig. 3B). Thus, TTX reduced fear expression when present during training but did not prevent the formation of fear associations.

\section{Inactivation of PL does not affect bar pressing or spontaneous locomotion}

Inactivation of PL before auditory and context conditioning had no effect on rates of bar pressing for food (ACSF, 18 presses/min; TTX, 22 presses $\left./ \mathrm{min} ; t_{(35)}=0.92 ; p=0.36\right)$. Inactivation also had no effect on locomotor behavior, because there were no differences in the number of line crosses in the open field (ACSF, 172 crosses; TTX, 154 crosses; $\left.t_{(18)}=0.62 ; p=0.54\right)$. Collectively, these results indicate that reduced freezing after PL inactivation was not attributable to changes in locomotor behavior or the motivation to press for food.

\section{Discussion}

We used pharmacological inactivation to determine the role of prelimbic activity in fear acquisition and expression. PL inactivation after conditioning reduced freezing to both a conditioned tone and a conditioned context but had no effect on freezing to a cat or avoidance of open spaces. Thus, PL activity is necessary for the expression of previously learned fears but not for the expression of innate fears. PL inactivation reduced fear expression during conditioning, but did not disrupt the formation of fear memories. This suggests that, although PL is critical for the expression of learned fear, it is not a critical site of plasticity underlying fear learning.

The lack of effect of PL inactivation on fear acquisition is similar to findings from studies using pretraining lesions (Morgan et al., 1993; Quirk et al., 2000). Our results suggest that the critical site of plasticity for classical fear conditioning lies outside PL, although PL may serve as a critical storage site in other fear conditioning paradigms, such as trace fear conditioning (Runyan et al., 2004) or olfactory conditioning (Laviolette et al., 2005). In contrast to PL, inactivation of the basolateral amygdala (BLA) blocks acquisition of fear to both auditory and contextual CSs (Helmstetter and Bellgowan, 1994; Wilensky et al., 1999). Thus, 
our effects are consistent with the notion that the critical plasticity for fear learning occurs in the amygdala (LeDoux, 2000; Goosens and Maren, 2003; Wilensky et al., 2006).

Despite the lack of effect on fear acquisition, inactivation of PL dramatically reduced the expression of fear to auditory and contextual CSs. Consistent with this finding, microstimulation of PL increases freezing to a conditioned tone (Vidal-Gonzalez et al., 2006), and inactivation of PL reduced freezing in a trace fear conditioning paradigm (Blum et al., 2006). PL could drive fear expression via its projections to the basal amygdala (BA) (McDonald et al., 1996; Vertes, 2004). In support of this, action potentials in PL neurons tend to precede those in BA neurons, indicating an excitatory connection between the two structures (Likhtik et al., 2005). Moreover, BA projects to the central nucleus of the amygdala, which in turn projects to subcortical and brainstem structures necessary for generating fear responses (LeDoux et al., 1988). Similar to our postconditioning inactivation of PL, postconditioning lesions of BA eliminate freezing to a conditioned tone (Anglada-Figueroa and Quirk, 2005). Thus, PL inputs to BA may be a key pathway for cortical modulation of fear expression. It is also possible, however, that fibers of passage originating rostral to PL may be involved, because they would likely have been affected by TTX infused into PL.

The lack of effect of PL inactivation on cat-evoked freezing suggests that expression of innate fear is mediated by a different pathway than conditioned fear. Unlike conditioned fear, predator fear does not appear to involve the BLA. Amygdala lesions that include the central and medial nuclei, but spare the BLA, block predator-evoked fear (Blanchard and Blanchard, 1972). Predator odors induce expression of immediate early genes in the medial nucleus (Dielenberg et al., 2001), and inactivation of the medial nucleus, but not the BLA, reduces freezing to a predator odor (Wallace and Rosen, 2001; Muller and Fendt, 2006). This could explain why PL, which projects to the BLA but not the medial nucleus (McDonald et al., 1996; Vertes, 2004), is important for learned, but not innate, fear.

PL receives convergent input from frontal areas, visual and auditory cortices, hippocampus, amygdala, thalamus, and hypothalamus (Conde et al., 1995). Thus, PL output likely reflects the integration of contextual, motivational, and mnemonic information. In support of this, stimulation of hippocampus can gate responses of PL neurons to BLA stimulation and vice versa (Ishikawa and Nakamura, 2003), and PL activity shows synchrony with hippocampal activity in a spatial working memory task (Jones and Wilson, 2005). The integration of sensory inputs with contextual and mnemonic information in PL may be necessary for determining the circumstances in which it is appropriate to express conditioned fear. After extinction, for example, fear expression is contextually regulated, and this regulation requires the hippocampus (Corcoran and Maren, 2001). Thus, integration of hippocampal and amygdalar projections in PL may be necessary for the conditional expression of fear to a CS. Such integration is apparently not required for unconditional fear responses to a predator.

In humans, mPFC is important for evaluating emotionally salient stimuli to select appropriate actions (Ochsner and Gross, 2005). During fear conditioning, the dorsal anterior cingulate cortex (dACC), which may be homologous to PL (Ongur and Price, 2000), shows robust activity (Buchel et al., 1999; Knight et al., 2004; Phelps et al., 2004; Birbaumer et al., 2005). Our data suggest that hyperactivity in AACC could contribute to amygdala hyperactivity, which underlies posttraumatic stress disorder (Shin et al., 2004). Reducing dACC activity might therefore be a useful strategy for the treatment of fear-related disorders, such as posttraumatic stress disorder and phobias (Straube et al., 2006).

\section{References}

Anglada-Figueroa D, Quirk GJ (2005) Lesions of the basal amygdala block expression of conditioned fear but not extinction. J Neurosci 25:9680-9685.

Baeg EH, Kim YB, Jang J, Kim HT, Mook-Jung I, Jung MW (2001) Fast spiking and regular spiking neural correlates of fear conditioning in the medial prefrontal cortex of the rat. Cereb Cortex 11:441-451.

Birbaumer N, Veit R, Lotze M, Erb M, Hermann C, Grodd W, Flor H (2005) Deficient fear conditioning in psychopathy: a functional magnetic resonance imaging study. Arch Gen Psychiatry 62:799-805.

Blanchard DC, Blanchard RJ (1972) Innate and conditioned reactions to threat in rats with amygdaloid lesions. J Comp Physiol Psychol 81:281-290.

Blum S, Hebert AE, Dash PK (2006) A role for the prefrontal cortex in recall of recent and remote memories. NeuroReport 17:341-344.

Buchel C, Dolan RJ, Armony JL, Friston KJ (1999) Amygdala-hippocampal involvement in human aversive trace conditioning revealed through event-related functional magnetic resonance imaging. J Neurosci 19:10869-10876

Campeau S, Davis M (1995) Involvement of subcortical and cortical afferents to the lateral nucleus of the amygdala in fear conditioning measured with fear-potentiated startle in rats trained concurrently with auditory and visual conditioned stimuli. J Neurosci 15:2312-2327.

Conde F, Maire-Lepoivre E, Audinat E, Crepel F (1995) Afferent connections of the medial frontal cortex of the rat. II. Cortical and subcortical afferents. J Comp Neurol 352:567-593.

Corcoran KA, Maren S (2001) Hippocampal inactivation disrupts contextual retrieval of fear memory after extinction. J Neurosci 21:1720-1726.

Dielenberg RA, Hunt GE, McGregor IS (2001) "When a rat smells a cat": the distribution of Fos immunoreactivity in rat brain following exposure to a predatory odor. Neuroscience 104:1085-1097.

Gilmartin MR, McEchron MD (2005) Single neurons in the medial prefrontal cortex of the rat exhibit tonic and phasic coding during trace fear conditioning. Behav Neurosci 119:1496-1510.

Goosens KA, Maren S (2001) Contextual and auditory fear conditioning are mediated by the lateral, basal, and central amygdaloid nuclei in rats. Learn Mem 8:148-155.

Goosens KA, Maren S (2003) Pretraining NMDA receptor blockade in the basolateral complex, but not the central nucleus, of the amygdala prevents savings of conditional fear. Behav Neurosci 117:738-750.

Helmstetter FJ, Bellgowan PS (1994) Effects of muscimol applied to the basolateral amygdala on acquisition and expression of contextual fear conditioning in rats. Behav Neurosci 108:1005-1009.

Ishikawa A, Nakamura S (2003) Convergence and interaction of hippocampal and amygdalar projections within the prefrontal cortex in the rat. J Neurosci 23:9987-9995.

Iwata J, LeDoux JE, Meeley MP, Arneric S, Reis DJ (1986) Intrinsic neurons in the amygdaloid field projected to by the medial geniculate body mediate emotional responses conditioned to acoustic stimuli. Brain Res 383:195-214.

Jones MW, Wilson MA (2005) Theta rhythms coordinate hippocampalprefrontal interactions in a spatial memory task. PLoS Biol 3:e402.

Kim M, Davis M (1993) Electrolytic lesions of the amygdala block acquisition and expression of fear-potentiated startle even with extensive training but do not prevent reacquisition. Behav Neurosci 107:580-595.

Knight DC, Cheng DT, Smith CN, Stein EA, Helmstetter FJ (2004) Neural substrates mediating human delay and trace fear conditioning. J Neurosci 24:218-228.

Laviolette SR, Lipski WJ, Grace AA (2005) A subpopulation of neurons in the medial prefrontal cortex encodes emotional learning with burst and frequency codes through a dopamine $\mathrm{D}_{4}$ receptor-dependent basolateral amygdala input. J Neurosci 25:6066-6075.

LeDoux JE (2000) Emotion circuits in the brain. Annu Rev Neurosci 23:155-184.

LeDoux JE, Iwata J, Cicchetti P, Reis DJ (1988) Different projections of the central amygdaloid nucleus mediate autonomic and behavioral correlates of conditioned fear. J Neurosci 8:2517-2529.

Likhtik E, Pelletier JG, Paz R, Pare D (2005) Prefrontal control of the amygdala. J Neurosci 25:7429-7437. 
McDonald AJ, Mascagni F, Guo L (1996) Projections of the medial and lateral prefrontal cortices to the amygdala: a Phaseolus vulgaris leucoagglutinin study in the rat. Neuroscience 71:55-75.

Morgan MA, Romanski LM, LeDoux JE (1993) Extinction of emotional learning: contribution of medial prefrontal cortex. Neurosci Lett 163:109-113.

Muller M, Fendt M (2006) Temporary inactivation of the medial and basolateral amygdala differentially affects TMT-induced fear behavior in rats. Behav Brain Res 167:57-62.

Ochsner KN, Gross JJ (2005) The cognitive control of emotion. Trends Cogn Sci 9:242-249.

Ongur D, Price JL (2000) The organization of networks within the orbital and medial prefrontal cortex of rats, monkeys and humans. Cereb Cortex 10:206-219.

Pentkowski NS, Blanchard DC, Lever C, Litvin Y, Blanchard RJ (2006) Effects of lesions to the dorsal and ventral hippocampus on defensive behaviors in rats. Eur J Neurosci 23:2185-2196.

Phelps EA, Delgado MR, Nearing KI, LeDoux JE (2004) Extinction learning in humans: role of the amygdala and vmPFC. Neuron 43:897-905.

Quirk GJ, Russo GK, Barron JL, Lebron K (2000) The role of ventromedial prefrontal cortex in the recovery of extinguished fear. J Neurosci 20:6225-6231.

Romanski LM, LeDoux JE (1992) Bilateral destruction of neocortical and perirhinal projection targets of the acoustic thalamus does not disrupt auditory fear conditioning. Neurosci Lett 142:228-232.

Rosen JB, Hitchcock JM, Miserendino MJ, Falls WA, Campeau S, Davis M (1992) Lesions of the perirhinal cortex but not of the frontal, medial prefrontal, visual, or insular cortex block fear-potentiated startle using a visual conditioned stimulus. J Neurosci 12:4624-4633.

Runyan JD, Moore AN, Dash PK (2004) A role for prefrontal cortex in memory storage for trace fear conditioning. J Neurosci 24:1288-1295.
Shin LM, Orr SP, Carson MA, Rauch SL, Macklin ML, Lasko NB, Peters PM, Metzger LJ, Dougherty DD, Cannistraro PA, Alpert NM, Fischman AJ, Pitman RK (2004) Regional cerebral blood flow in the amygdala and medial prefrontal cortex during traumatic imagery in male and female Vietnam veterans with PTSD. Arch Gen Psychiatry 61:168-176.

Sierra-Mercado Jr D, Corcoran KA, Lebron-Milad K, Quirk GJ (2006) Inactivation of the ventromedial prefrontal cortex reduces expression of conditioned fear and impairs subsequent recall of extinction. Eur J Neurosci 24:1751-1758.

Straube T, Glauer M, Dilger S, Mentzel HJ, Miltner WH (2006) Effects of cognitive-behavioral therapy on brain activation in specific phobia. NeuroImage 29:125-135.

Swanson LW (1992) Brain maps: structure of the rat brain. New York: Elsevier.

Vertes RP (2004) Differential projections of the infralimbic and prelimbic cortex in the rat. Synapse 51:32-58.

Vidal-Gonzalez I, Vidal-Gonzalez B, Rauch SL, Quirk GJ (2006) Microstimulation reveals opposing influences of prelimbic and infralimbic cortex on the expression of conditioned fear. Learn Mem 13:728-733.

Wallace KJ, Rosen JB (2001) Neurotoxic lesions of the lateral nucleus of the amygdala decrease conditioned fear but not unconditioned fear of a predator odor: comparison with electrolytic lesions. J Neurosci 21:3619-3627.

Wilensky AE, Schafe GE, LeDoux JE (1999) Functional inactivation of the amygdala before but not after auditory fear conditioning prevents memory formation. J Neurosci 19:RC48(1-5).

Wilensky AE, Schafe GE, Kristensen MP, LeDoux JE (2006) Rethinking the fear circuit: the central nucleus of the amygdala is required for the acquisition, consolidation, and expression of pavlovian fear conditioning. J Neurosci 26:12387-12396. 